\title{
Capital fictício e urbanização ou dos diversos usos do território
}

Capital fictif et urbanisation ou les différents usages du territoire Fictive capital and urbanization, or the different uses of territory Capital ficticio y urbanización o los diversos usos del territorio

\section{Rosângela Viana Vieira Neri e Fábio Marvulle Bueno}

\section{(2) OpenEdition}

Journals

Edição electrónica

URL: http://journals.openedition.org/espacoeconomia/469

DOI: $10.4000 /$ espacoeconomia.469

ISSN: 2317-7837

\section{Editora}

Núcleo de Pesquisa Espaço \& Economia

\section{Refêrencia eletrónica}

Rosângela Viana Vieira Neri e Fábio Marvulle Bueno, « Capital fictício e urbanização ou dos diversos usos do território », Espaço e Economia [Online], 3 | 2013, posto online no dia 19 dezembro 2013, consultado o 01 maio 2019. URL : http://journals.openedition.org/espacoeconomia/469 ; DOI :

10.4000/espacoeconomia.469

Este documento foi criado de forma automática no dia 1 Maio 2019.

(C) NUPEE 


\title{
Capital fictício e urbanização ou dos diversos usos do território
}

\author{
Capital fictif et urbanisation ou les différents usages du territoire \\ Fictive capital and urbanization, or the different uses of territory \\ Capital ficticio y urbanización o los diversos usos del territorio
}

Rosângela Viana Vieira Neri e Fábio Marvulle Bueno

\section{Introdução}

1 Este ensaio busca compreender a organização do território, especificamente o território urbano, nas condições das relações capitalistas contemporâneas em que a forma fictícia do capital ganha relevância. Assim, como expressão fenomênica, comum a qualquer mercadoria, ${ }^{1}$ o processo de valorização do espaço, bem como sua fluidez incessante e inerente às relações sociais, também articula e contém as questões relativas à criação de valor-capital, ao trabalho e às classes sociais. As interações específicas entre a forma fictícia do capital e o uso do território urbano, especialmente o modo como as políticas urbanas são influenciadas pelo capital fictício na organização do espaço das cidades, são nossa principal preocupação.

2 Nosso recorte é permeado pela tese de um profundo entrelaçamento entre a organização do espaço urbano e os interesses do capital. o desenvolvimento imposto pela globalização coloca para os gestores urbanos a necessidade de criar, nos termos de David Harvey (2005), "chamarizes" para o capital, tornando as cidades atraentes para o fluxo do capital e as decisões dos gestores públicos parte do processo de valorização do capital, pois direcionam os recursos públicos para o estabelecimento de uma infraestrutura que organiza o espaço urbano na forma de investimento imobiliário ${ }^{2}$ e espaço para o funcionamento de grandes empresas (principalmente dos serviços financeiros).

3 As formas criadas na cidade, tais como vias de transporte, setor de serviços, centros de comunicação, de tecnologia e de saber (principalmente aqueles voltados para as finanças 
e produção tecnológica), tornam-se os "chamarizes" para o capital. A análise do Plano Piloto de Brasília, pela sua estrutura urbanística, evidencia esse processo.

4 Se as políticas públicas que organizam o espaço urbano seguem a dinâmica ditada pelo capital em geral e pelas suas formas concretas, a Teoria do Valor Trabalho (TVT), eixo sob o qual a análise marxista sobre o funcionamento do modo de produção capitalista em geral e seu desenvolvimento histórico concreto mostra-se um elemento de suma importância para entendermos a dinâmica dessa força motriz de organização do espaço urbano e da cidade.

5 Muitos autores nomeiam a atual fase histórica do capitalismo como globalização financeira, destacando entre suas características marcantes a ascensão a uma posição hegemônica da fração ligada ao capital portador de juros perante as demais frações. A dinâmica capitalista sob a égide dessa fração é marcada por novas formas de organização da produção e gestão da força de trabalho (toyotismo/acumulação flexível), aumento da mobilidade internacional de capital, incorporação de novas fronteiras de acumulação a partir de regiões antes isoladas do mercado internacional (antigo Leste europeu e da China), uma nova rodada de expansão das grandes empresas multinacionais para a periferia capitalista, e a expansão exacerbada daquilo que Marx denominou capital fictício.

6 Sendo o capital em geral uma força central na organização do espaço, de que maneira a expansão da forma fictícia do capital afetaria a urbanização? Como se daria sua influência nas políticas urbanas de organização do espaço?

\section{Do capital fictício}

7 Marx, no Livro III de 0 Capital, expõe o processo de autonomização das funções de comércio de mercadorias e de dinheiro dentro do capital industrial, constituindo, respectivamente, o capital comercial e o capital portador de juros. Este se especializa em emprestar dinheiro para ser usado como capital, apropriando-se de parte da mais-valia gerada pelo capital produtivo em forma de juros. O processo de desenvolvimento do capital portador de juros, que traz a aparência da mera propriedade do capital como fonte de mais-valia, acaba se desdobrando no surgimento daquilo que Marx chama de capital fictício. A sociedade capitalista, influenciada pela disseminação e pela configuração do capital portador de juros, passa a interpretar e conceder a qualidade de juros a todo e qualquer fluxo de rendimento. Com isso, imputa-se idealmente um determinado volume de capital como origem desse fluxo de rendimento, e tal capital ilusório passa a ser negociado como se de fato fosse um capital qualitativamente igual a qualquer outro.

8 A ilusão do capital fictício acaba tomando concretude e singularidade; primeiro, por reforçar a aparência de que o capital valoriza-se por si, independentemente da produção e, assim, a expensas do trabalho criador de mais-valia (Carcanholo \& Sabadini, 2009); segundo, pela autonomia de sua valorização perante a dinâmica dos demais capitais, decorrente do componente especulativo inerente ao capital fictício; e, terceiro, pela possibilidade de venda ou realização do capital fictício, inerente a qualquer outra forma de valor-capital ${ }^{3}$ substantivado e autônomo (Carcanholo \& Nakatani, 1998, p. 307), convertendo-se em capital real na forma de investimentos em equipamentos, bens (inclusive imóveis) ou serviços que apresentem a perspectiva de lucro futuro (Harvey, 2005, p.171). 
9 Marx mostrou os títulos da dívida pública e as ações negociadas em bolsa como formas concretas de capital fictício. Ambos são títulos respaldados juridicamente, que dão direito a um fluxo de rendimento. No caso da dívida pública, o montante aplicado nunca assumiu a forma de elementos do capital constante e variável, ficando mais evidente o sentido fictício assumido pelos títulos encarados como capital. Já as ações têm ligação com um montante de capital plasmado em elemento constante e variável, mas acabam se autonomizando e sendo vistas elas próprias como capital. Esse jogo dialético de presençaausência de articulação entre a materialidade da riqueza e sua acumulação em escala cada vez mais valorada é necessário ao capital fictício e às suas determinações.

Cabe enfatizar que, de acordo com Carcanholo e Sabadini (2009, p. 43), o capital fictício em nada contribui para a produção de mais-valia. Sua forma física e legal são os títulos comercializáveis, que tornam capital aquilo que não é, ao mesmo tempo em que fornece a concretude aparente e a representação social. Mais que o capital portador de juros, o capital fictício cria uma ideia de separação inexistente com a dinâmica da produção ${ }^{4}$ devido ao seu componente especulativo.

11 Para Carcanholo e Nakatani (1998, p. 305), o próprio capital necessário à reprodução do capital produtivo passa a atuar segundo a lógica especulativa, onde "localiza-se" o capital fictício. Este fato engendraria o capitalismo contemporâneo em uma simultaneidade entre a realização do produto e a capitalização financeira. Em consonância com esse movimento ampliam-se o consumo e a exploração do trabalho ${ }^{5}$.

\section{Espaço e capital fictício}

12 Na cidade, principalmente nas metrópoles, ${ }^{6}$ o processo de urbanização do seu território tanto afeta a expectativa de valorização das diversas frações do capital (tomando-se os imóveis como forma de investimento, tanto quanto motivações de moradia ou atividade de produção), como sofre influência da presença dos mesmos (Arranjos Produtivos Locais e as economias de aglomeração, passando pelas políticas públicas de uso do solo e concessão de benefícios ao setor privado, chegando às cadeias produtivas globais e seu impacto na infraestrutura).

13 Na atual fase do capitalismo, a ascensão hegemônica do capital portador de juros e a disseminação das formas fictícias imprimem ao conjunto dos capitais uma dinâmica de acumulação na qual a intensificação da exploração do trabalho e da concorrência intercapitalista são marcas indeléveis.

14 Em que pese o capital fictício estar presente também naqueles blocos de capitais (grandes empresas) envolvidos diretamente no âmbito da produção, seu processo de autonomização do capital fictício gerou uma fração específica de capitalistas, que Chesnais (2005) denomina investidores institucionais, abarcando fundos de investimento, de pensões, de hedge e grandes bancos. Essas instituições necessitam estabelecer locais para o funcionamento de seus centros de decisões, em forma de escritórios, complexos ou centros empresariais, a partir dos quais irradiam comandos para a realização de negócios nos mercados globais, alocando seus recursos nos mais diferentes mercados nacionais em busca de ganhos.

Com isso, o capital fictício passa a gerar um processo específico de organização do território em que instala seus centros decisórios, paralelo e imbricado com a organização urbana para a atração de outras formas de capital. 0 território passa a requerer uma 
organização que contemple 1) infraestrutura que assegure o fluxo de informações, implicando redes de comunicação e serviços de informática específicos; 2) mobilidade de quem está envolvido nas atividades decisórias, com rede de transporte de rotas internacionais; 3) ambiente de "ordem social" e tranquilidade que não interfira nas atividades desses centros decisórios; 4) moradia adequada para esses executivos. Além disso, as instituições envolvidas com o capital fictício privilegiam outras dimensões territoriais que restringem a possibilidade de alocação de seus centros decisórios, como a presença de instâncias de poder político estatal em cidades de grande porte.

Uma vez que a objetivação e a realidade do capital fictício criam sentidos amplos em espaços-tempos diversos e confluentes, ressalta o fato de que a pluralidade de tempo se dá em função não de um passado que ainda orienta, mas que, por força da condição espacial, permanece e que também mantém a estrutura social. A nosso ver, é isto que torna possível a conexão global-local no cotidiano vivido em cada cidade e que permeia as singularidades dos lugares. Aqui as insignificâncias das formas das coisas voltam ser o chão deste mundo. Chão (espaço) produzido e reproduzido como condição, meio e produto das relações sociais, de partes socialmente criadas e aparentemente fragmentadas, pois se congregam em sistemas funcionais justapostos. Assim, terra, capital e trabalho passam a aparecer tal como são: articulados e configurados nas relações sociais e não como coisas produzindo coisas.

17 A urbanização, como lógica instrumental do uso do espaço que articula as formas e os conteúdos dados pela acumulação, possibilita à lógica financeira materializar-se também na mercadoria espaço, criando a ilusão de rendimento ou lucro certo em relação a essas formas urbanas.

Comprar um escritório em um edifício corporativo ou mobilizar recursos públicos para a construção de Centros de Convenções, ou mesmo ceder lotes e infraestrutura para a iniciativa privada construir e explorar áreas de comércio, serviços e lazer (estádios esportivos, por exemplo) nas quais se aliam, em um mesmo complexo, edifícios de escritórios e hotéis, tornam-se possibilidades 'certas' de retorno valorativo futuro em uma cidade competitiva.

19 Por esse mesmo viés existem as chamadas parcerias público-privadas, nas quais a legitimidade nesse tipo de consórcio é dada na perspectiva de geração de emprego e renda. Contudo, a grande maioria dos empregos que são gerados é de baixa remuneração (seguranças, faxineiros, garçons, manobristas, camareiras, entre outros), o que obriga os trabalhadores a trabalharem horas extras e, muitas vezes, sob contratos temporários e sem laços com seus sindicatos. Também em sua grande maioria o poder público arca com os riscos, e a iniciativa privada, com os lucros. Viana (2008), ao analisar o Setor de Hotéis e Turismo Norte (SHTN) em Brasília, confirmar tal afirmativa.

A presença no Plano Piloto de Brasília de escolas voltadas para negócios (do tipo IBMEC ou Fundação Universa ${ }^{7}$ ) ou de um complexo empresarial como o Brasil $21,{ }^{8}$ é forte indício da presença do capital fictício nos negócios da urbanização. Mostra que o capital (como relação social de produção) precisa criar continuamente sua reprodução e valoração, e isso significa submeter mais e mais o processo de trabalho ao processo de valorização dos objetos, tendo como centro a reprodução social ou a reprodução da relação capitalista.

21 A construção de modernos edifícios no centro do Plano Piloto e mesmo nas áreas comerciais das quadras residenciais, voltados para escritórios ou serviços sofisticados, em ritmo acelerado (que implica quase sempre acidentes de trabalho e torna compreensível o 
déficit habitacional para as classes menos favorecidas da cidade), é assegurada pelo plano urbanístico tombado. É nesse sentido que tombamento e crédito podem influir na alta do preço de mercado das mercadorias ou ativos, ${ }^{9}$ a exemplo do mercado imobiliário. A oferta de crédito direcionado a este setor eleva a cotação dos preços dos imóveis e induz o sobreinvestimento empresarial ou imobiliário, fazendo de porções de espaço ${ }^{10}$ mercadoria.

É de conhecimento geral que os problemas do setor imobiliário estão na propriedade privada e na imobilização dos recursos do produtor há um longo tempo, que o torna dependente de financiamento e ainda mais da certeza da venda. Por isso, em um primeiro momento, o capital imobiliário precisa da integração com o capital financeiro para viabilizar sua produção. Essa necessidade de produzir (como qualquer outro setor) leva o setor imobiliário a diminuir o tempo útil dos imóveis por meio da criação de novas necessidades na sociedade (o que, de certa maneira, faz aumentar a exploração do trabalhador). Essas "necessidades" coadunam com os excedentes de capital global que, em busca de mercados, aportam onde haja as conhecidas condições, tais como força de trabalho, infraestrutura, economia de débito, políticas urbanas favoráveis para liberar porções do território na cidade.

23 No âmbito da totalidade dos capitais, Harvey (2005, p.172) analisa a produção contínua de infraestrutura e a aquisição de bens de capital na América Latina, com empréstimos coletados nos mercados de capitais de Londres ou de Nova Iorque ("por meio da formação de capital fictício"), como forma de absorção da superacumulação. Na escala local observa-se uma repetição desse processo. As demandas da centralidade das frações de capitais locais fazem surgir outras relocalizações. Assim, resolvem localmente o problema estrangeiro de superacumulação, ainda que momentaneamente, e transmitem segurança para investimentos neste setor em épocas de crise. Também passam a influenciar e mesmo a direcionar as políticas urbanas para que áreas passíveis de serem construídas sejam liberadas via plano diretor.

24 A cidade, além da sua morfologia, revela o sentido e o uso do espaço urbano e sua integração territorial e des-re-territorial, ${ }^{11}$ e é nesse recorte que a escala define nossa questão. Esta definição aponta a lógica capitalista e seu movimento no tempo e no espaço. Não em uma proposição na qual o capital induz a escala ou a escala engendra a cidade, mas o par formado por cidade e território é uma análise escalar das formas locais da reprodução das relações sociais na prática socioespacial. Significa dizer que a análise do espaço social - lugar da reprodução das relações de produção (Lefebvre, 1973, p. 170) -desvela a (in)coerência imposta pela gestão territorial na prática espacial, a saber, a cidade.

25 A urbanização consolidou na construção de Brasília seu lugar como setor produtivo. Sob o comando do capital, a urbanização aqui desenvolvida remete a contradições dadas nas e pelas necessidades dos cidadãos, as desigualdades e os conflitos. Evidentemente, surgem os movimentos sociais contrários a essa política urbanizatória e composição territorial, ainda que imersos na lógica própria do Capitalismo. Nesses circuitos de valorização de capitais a dificuldade de compreender a sobreposição entre global e local na esfera das frações de capital e sua territorialização encaminha a análise para a tensão entre a construção das infraestruturas urbanas -- propriedade social -- e sua realização no espaço privado, tornada assim elemento de mediação. essa associação ao processo de urbanização. Segundo Harvey (2005, p.165), essa 
articulação torna-se dialeticamente empecilho, uma vez que no movimento da vida, do tempo e do espaço, as condições históricas são criadas na sociedade e têm normas. Dessa maneira, aquilo que no passado foi norma de facilitação das ações capitalistas torna-se, no presente, obstáculo. No Plano Piloto de Brasília o tombamento do seu projeto urbanístico configura um obstáculo considerável. Neste sentido é que as políticas urbanas precisam estar articuladas aos pressupostos do tombamento, bem como às frações de capitais.

Para o governo local, manter a urbanização no Plano Piloto é oneroso. A busca por aporte de capitais não pode ser descartada. Ao mesmo tempo, o estabelecimento de condições favoráveis à produção capitalista passa a demandar outras representações que perpassam o visível, as leis e a legitimidade social. Não se trata então de descrever os "malabarismos" engendrados na urbanização, mas seus diferentes usos. Tal como a teoria marxiana realiza a respeito da mercadoria, significa pensar a urbanização construindo e formando a tessitura da matéria da riqueza por meio do valor.

São estes os conteúdos das estratégias que dizem respeito a uma tentativa de reproduzir suas principais linhas de força no espaço da cidade e, com isto, atrair para esta o montante de capital necessário às novas adequações. Tais adequações precisam equalizar os conteúdos e as formas da refuncionalização do espaço mantendo, contudo, o mesmo modelo civilizatório capitalista e da cidade patrimônio da humanidade. A duplicidade em que a forma (visível) na qual a mercadoria espaço, a nosso ver, participa no processo de extensão da cidade aparece em sua interpretação comum. Por isso obscurece a potência daquilo que o espaço urbano congrega e condiciona. Isso permite a realização de novos ajustes. Outras determinações aparecem na ordem de relações entre normas urbanísticas, no cotidiano e nas condições de acumulação capitalista para a re-produção do espaço, quase em condições de equilíbrio, com as mudanças mais expressivas ocorridas na sociedade.

29 A investigação do sentido da propriedade privada do espaço urbano na constituição da cidade de Brasília pode possibilitar o entendimento de uma produção espacial peculiar na qual a própria urbanização é transformada em um setor produtivo. Ao definir-se nos termos das práticas sociais que constituem a cidade o espaço concebido organizado, para fragmentar e hierarquizar todo o tecido urbano de Brasília no primado da técnica, este se transforma em política para a lógica acumulativa do capital. Nestes termos o diálogo apenas se inicia. Significa também refletir sobre a apropriação do espaço plena do sentido humano, que por essa razão cria a contradição entre o uso do espaço para a realização da vida humana e como condição da reprodução do capital, processo sempre em constituição da sociedade urbana (Carlos, 2004).

\section{Por uma análise das porções da cidade como mercadorias}

30 A análise não pode desconsiderar dois fatores elementares. Primeiro que cada lugar é resultado de uma série de variáveis que determinam e são determinadas pelo espaço que ocupam, embora diga respeito a uma ordem distante. Por isso, dizer que o processo capitalista se realiza da mesma maneira para todas as partes do mundo é generalizar e esquecer que cada lugar se define como parte integrante da divisão espacial do trabalho. Entretanto, as partes são e fazem parte do capitalismo, como uma totalidade, daí o porquê dessas subdivisões e diferenciações. 
31 Assim, não se pode prescindir e negar que as cidades têm constituições diferentes de conformação e organização devido ao conteúdo de suas relações sociais, ainda que toda cidade entre nas relações capitalistas em forma de mercadoria.

Em Marx (Livro I, v.1), a mercadoria é um objeto externo, portanto coisa, ${ }^{12}$ oriunda do trabalho, considerada segundo sua qualidade, que pode ser variada e de quantidade múltipla. Deve estar relacionada, na análise, ao tempo histórico e socialmente reconhecido. É importante que a mercadoria e seu valor sejam algo socialmente tratado como tal para que possam ser trocados por outra coisa também considerada da mesma natureza e iguais na relação.

o que torna uma coisa mercadoria, na teoria marxiana, é a sua utilidade (valor-de-uso), independentemente da sua quantidade. É a função do seu uso que torna essa oisa veículo material do valor-de-troca (op. cit., p.58). 0 valor-de-troca expressa o significado de igual (id., p. 59) e é forma da expressão da coisa da qual ele se separa, pois diz respeito a quantidade. A coisa torna-se valor-mercadoria (idem, p. 60) quando toma a forma do trabalho humano abstrato. Marx ressalta que no momento da troca de mercadorias a sua utilidade é desprendida do seu valor-de-troca (relação de permuta).

Quando o espaço da cidade é loteado, mesmo que no Plano Piloto de Brasília se vendam projeções, suas porções só podem ser vendidas se se apresentarem no mercado como mercadoria (com as características anteriormente descritas). Nesse contexto, o espaço urbano é valor, "ao [qual] não importa a forma específica do valor-de-uso em que se manifesta" (id., p.85), mas que se cristaliza em forma de objeto (op. cit., p. 73). Dizer que o espaço produz valor é um erro, pois o trabalho social nele incorporado é que o produz: "como valores, as mercadorias são apenas dimensões do tempo de trabalho que nelas se cristaliza" (ibid., p. 61). As representações criadas em torno da valoração do espaço e que se materializam no preço dos imóveis são, a princípio, materializadas e protegidas em forma de propriedade privada e apresentadas como obras de urbanismo (melhor seria dizer capitalização ou condições de monopólio para as diversas frações do capital).

Aceito agora como mercadoria, o espaço pode ser entendido na criação de sobrevalor e no reino amplo da especulação imobiliária. Em Brasília, o governo ainda é o proprietário de grande parte de suas terras, a transformação da renda fundiária em lucro está diretamente ligada às políticas de planejamento urbano e, portanto, o governo continua a ser um agente imobiliário. ${ }^{13}$ Isto fez com que a socialização dos custos de produção alcançasse patamares outros quando pensada em relação a outras metrópoles. No Modelo de Gestão Estratégia do território do Distrito Federal (2004, p. 59) a busca por maior flexibilidade para o uso da região central -- ou seja, o Plano Piloto -- traduz uma vontade política de atender a demanda do modelo atual de reprodução capitalista:

Convém observar que o desempenho da economia brasiliense no período de 1980 a 1990, e mesmo entre 1990 e 2000, decorreu, em parte, das facilidades de instalação do setor de serviços na capital, atraídas pelos negócios gerados pela administração federal. Tal condição, para o futuro, parece comprometida, devido às dificuldades à oferta de novas áreas na região central da cidade. Há ainda que se considerar a inércia da estrutura urbana, ou seja, ela não muda com a rapidez exigida para o atendimento das novas demandas, sendo que o tombamento da área central, na prática, restringe algumas remodelações que poderiam atender essas demandas (grifos nossos).

Assim, a prática da política urbana e a prática econômica se diluem diante dos amplos e diferentes interesses e projetos que permeiam os membros da classe política e os capitais envolvidos e favorecem a acumulação. A análise assinala as ações do poder público local 
associado na maneira como os capitais retiram sua valorização da cidade, tornando-se atores centrais nos encaminhamentos políticos:

Algumas firmas nacionais e transnacionais ainda requerem lugares centrais para a sua localização, onde possam estabelecer uma espécie de base estratégica com alta concentração de meios, sobretudo de infraestrutura vinculada ao sistema de comunicações e de serviços especializados. [...] Assim, Brasília pode oferecer importantes vantagens na atração de firmas nacionais e internacionais e de oportunidades de investimento, principalmente se considerarmos que a cidade oferece ótimas condições de infraestrutura, saneamento, rede de comunicações e energia (Secretaria de Desenvolvimento Urbano e Habitação, Modelo de Gestão Estratégia do Território do Distrito Federal, 2004, p. 59-60) (grifos nossos).

Essa adequação do território do Plano Piloto às empresas do setor terciário moderno, como parte do fundamento da metrópole atual, precisa oferecer qualidade de vida, que se traduz em um habitat condizente com essa classe social. Esta é a ligação entre a renda territorial urbana e a valorização futura da criação do Setor de Habitações Coletivas Noroeste. ${ }^{14}$ Vemos na criação desse Setor o discurso ambientalista a justificar o continuísmo da extração de renda da terra urbana, além de atrair empresas de outros estados - principalmente São Paulo -, solidificando, assim, o amplo conceito de cidade como negócio, para construir o novo bairro da capital e "reforçar o conceito do ecologicamente correto", mas socialmente seletivo.

Em um processo contínuo de adequação, também a infraestrutura urbana deve proporcionar um sistema de transporte ágil e eficiente e uma rede de telecomunicações que atenda aos fluxos financeiros ${ }^{15}$ na metrópole. Isso pode ser observado com a ampliação de certas vias no Plano Piloto e no novo modelo de trem de superfície, que ligará o aeroporto, os setores hoteleiros do Plano Piloto e o estádio Mané Garrincha, passando pela avenida W3 Sul ${ }^{16}$. A própria vinda da TAP Portugal ${ }^{17}$ para Brasília reabre o Aeroporto Juscelino Kubitschek para vôos internacionais e cria uma ligação direta com a Europa, além do fato de o sistema informacional já estar bem consolidado na cidade.

A gestão política da cidade é assim materializada em várias de suas porções, possibilitando que se mostre a influência concreta do capital fictício na urbanização de Brasília, uma vez que estão presentes na plataforma de eficiência governamental a gestão dos recursos públicos e os ajustes econômicos. Esses ajustes econômicos, como foi mostrado, visam priorizar o desenvolvimento econômico via setor terciário sofisticado a expensas do desenvolvimento social. Ressalte-se que, sob esses determinantes, o conceito de qualidade de vida volta-se para uma sustentabilidade do próprio mercado imobiliário e do próprio governo.

Como fazer com a contradição crescente frente à intensificação da exclusão social provocada pelo capitalismo atual e a necessidade de "integração social?" Recorre-se à imagem do culto ao civismo ou patriotismo de cidade. Para Borja e Castells (1996, p. 160), essa promoção do civismo interno, no qual a monumentalidade do Plano Piloto é incontestável,

deve apoiar-se em obras e serviços visíveis, tanto os que têm caráter monumental ou simbólico como os dirigidos a melhorar a qualidade dos espaços públicos e o bem-estar da população.

41 A urbanização se processa por meio de um discurso que se legitima e no qual a qualidade de vida e a concentração e a escassez relativa da terra ampliam e tornam reais o sentido da propriedade, o arcabouço da gestão estratégica e da territorialização dos capitais. Também mostra uma modernização que, ao buscar a realização do terciário moderno, 
tende a uma seleção de habitantes devido aos altos preços das moradias - ainda que especulativa - para Brasília que oferece uma ampliação da exclusão social pelo tempo e espaço da metrópole, unificando no território a proeminência dos sistemas técnicos e da informação aos subespaços sofisticados de trabalho (a partir dos escritórios, como aqueles oferecidos no Centro de Eventos e Convenções Brasil 21, por exemplo). Tal configuração confirma o impulso em direção ao desenvolvimento de um terciário sofisticado que é ao mesmo tempo um movimento de valorização imobiliária, componente-chave para a compreensão do espaço metropolitano e de materialização do capital fictício.

As formas, as funções e os conteúdos que se manifestam nos artefatos urbanos, como hotéis, flats, condomínios fechados, shopping centers, centros de pesquisa, centros de convenções, escritórios sofisticados, parques públicos, alargamento das vias de transporte, etc., participam do processo socioespacial em que a propriedade imobiliária constitui e institui as formas sociais de produção e apropriação da cidade. Urbanisticamente, uma cidade organizada e produzida a partir de um processo que integra economia e política em função da reprodução das condições sociais e gerais de produção. A representação mostra-se tal como é: uma intermediação entre abstrato concreto e sua materialidade, na qual a continuação da produção imobiliária busca materializar parte das operações financeiras de alhures.

\section{BIBLIOGRAFIA}

ANDAKU, C. A.; BUENO, F. M. Capital fictício em duas interpretações do capitalismo contemporâneo. VI Colóquio Internacional Marx e Engels, 2009.

BORJA, J., CASTELLS, M. As cidades como atores políticos. Novos Estudos - Cebrap. São Paulo: Editora Brasileira de Ciências, n.45, jul./1996.

CARCANHOLO, R. A., NAKATANI, P. O capital especulativo parasitário: uma precisão teórica sobre o capital financeiro, característico da Globalização. Anais do III Encontro Nacional de Economia Política. Niterói: Eduff,1998. V. I, p.304-16.

SABADINI, M. S. Capital fictício e lucros fictícios. Rev. Soc. Bras. Economia Política, Rio de Janeiro, no 24, p. 41-65, junho/2009.

CARLOS, A. F. A. O espaço urbano: novos escritos sobre a cidade. São Paulo: Hucitec, 2004.

COSTA, L. Brasilia Revisitada. Disponível em: <www.copevdf.com.br/coordenacao/pdot_pdls/ dec_10829.htm>. Acesso em 30/5/2009.

CHESNAIS, F. (org.). A finança mundializada - raízes sociais e políticas, configuração, consequências. São Paulo: Boitempo, 2005.

GOVERNO do Distrito Federal, Secretaria de Estado de Desenvolvimento Urbano e Habitação Seduh. Secretaria de Política Urbana e Informação - SUPIN. Modelo de Gestão Estratégica do Território do Distrito Federal. Brasília: Metroquattro Arquitetura Tecnologia, 2004.

HARVEY, D. Condição pós-moderna: uma pesquisa sobre as origens da mudança cultural. São Paulo: Edições Loyola, 2005. 
. Do administrativo ao empresariamento: a transformação da governança urbana no capitalismo tardio. In: HARVEY, David. A produção capitalista do espaço. São Paulo: Anablume, 2005 (1989). p. 163-90.

HAESBAERT, R.; GONÇALVES-PORTO, C. W. A nova des-ordem mundial. São Paulo: Editora Unesp, 2006.

LEFÈBVRE, H. A reprodução das relações de produção. Porto: Publicações Escorpião, 1973.

Marx, K. O Capital: crítica da economia política. 24. ed. Livro I [O processo de produção do capital], vol. 1. Rio de Janeiro: Civilização Brasileira, 2006.

VIANA, R. A re-produção do espaço como mercadoria: Polo 3 - Projeto Orla Extensões-Latências. 2008. 231 f. Dissertação (Mestrado em Geografia) - Programa de Pós-Graduação em GeografiaUniversidade de Brasília, Brasília-DF, 2008.

\section{NOTAS}

1. Segundo Marx (O Capital, Livro I, Volume I), tudo pode se tornar uma mercadoria capitalista.

2. De acordo com Botelho (2007, p. 25), o setor imobiliário trata do "conjunto de atividades que envolvem os subsetores de materiais de construção, de construção de edifícios e obras de engenharia civil, bem como aqueles ligados ao terciário, tais como atividades de manutenção predial". A importância relativa e significações desse setor podem ser verificadas no percentual que congrega o PIB brasileiro disponibilizado pelas pesquisas do Dieese, bem como por meio do Índice Geral do Mercado Imobiliário (IGMI-C), indicador de rentabilidade do setor imobiliário brasileiro, desenvolvido pelo Instituto Brasileiro de Economia (Ibre/FGV).

3. Para Marx (O Capital [2008], Livro 1, v.2 e Livro 2) o capital é valor que circula. É tornado valor com o desenvolvimento das relações mercantis na sociedade, pois resulta de uma circulação tal em que se autovaloriza e se substantiviza, pois o próprio valor transforma-se em substantivo. Em Carcanholo; Nakatani (1998, p.308), “o conceito de capital expressa valor em determinado estágio de seu desenvolvimento e consiste em uma relação social expressa que se substantiva".

4. Chamamos a atenção do leitor para o fato de que não consideramos capital fictício sujeito, e sim algo que é e se constitui na relação social. Como o capital fictício submete, por ser real e fictício, o capital produtivo (Carcanholo \& Nakatani, 1998), não deve ser entendido como ação de um sujeito, mas do movimento existente no processo atual de mundialização de capitais.

5. Exploração dada principalmente pela flexibilidade do trabalho que se torna a base da acumulação por espoliação (ou acumulação primitiva: um processo em andamento analisada por Harvey [2005, p.115-148]), como que aprimorada e que necessita de maiores escrutínios nos quais o trabalho aparece como miséria absoluta e constitui negatividade.

6. O destaque que damos às metrópoles se explica por serem estas nosso objeto de estudo há algum tempo. Evidentemente, não se pode menosprezar as cidades médias e pequenas que, com características distintas, entram no circuito produtivo capitalista por meio da re-valorização do seu espaço.

7. Trata-se de instituições com especificidades próprias que visam à formação e qualificação de profissionais na área de economia e negócios.

8. Segundo o sítio deste empreendimento: "Concebido dentro do mais moderno conceito de business e hotelaria, o Brasil 21 é composto de três edifícios de flats, três torres de escritórios, um centro de convenções, setenta e duas lojas, cinemas, infraestrutura de lazer e três subsolos de garagem com serviços de valet parking. Já estão em pleno funcionamento as torres Tryp Brasil 21, Business Center Park, Business Center Tower e Meliá Brasil 21. O projeto está sendo concebido 
pela ARCA Empreendimentos Imobiliários e pela Construtora Paulo Octávio. http:// www.convencoesbrasil21.com.br/cen-centro/complexo.html. Acesso em 10/7/2011.

9. Para Sandroni (2005, p.50), ativo se refere a um "conjunto de bens, valores, créditos e semelhantes, que formam o patrimônio de uma empresa, opondo-se ao passivo (dívidas, obrigações etc.)."

10. Essas porções de espaço são comercializáveis na forma conhecida de loteamentos, regulamentados ou não por lei, mas garantidos pelo direito à propriedade, uma vez que esse processo as transformam em mercadorias.

11. De acordo com Haesbaert \& Gonçalves (2006, p.131), a des-re-territorialização é um "processo concomitante de destruição e reconstrução de territórios", analisado na "ideia de território como processo ao mesmo tempo de domínio (político-econômico) e apropriação (simbólica) do espaço". 12. O destaque, na teoria marxiana, para coisa externa ao ser demarca sua preocupação em ir da aparência à essência da mercadoria e determinar bem os parâmetros de como desenvolverá os termos relativos ao fetichismo e mesmo à alienação postos inicialmente na natureza do trabalho humano abstrato (O Capital, Livro I, v.1, 2005, p.60): "Se prescindirmos do valor-de-uso da mercadoria, só lhe resta ainda a propriedade, a de ser produto do trabalho. [...] desvanecem-se, portanto, as diferentes formas de trabalho concreto, elas não mais se distinguem umas das outras, mas reduzem-se, todas, a uma única espécie de trabalho, o trabalho humano abstrato".

13. Ver, a esse respeito, dissertação de mestrado de Viana "A (re)produção do espaço como mercadoria: Polo 3 - Projeto Orla Extensões-Latências” de 2008, p.7.

14. Este setor habitacional ainda se encontra em fase de construção. $O$ empreendimento deverá render à Companhia Imobiliária do Distrito Federal (Terracap) cerca de $\mathrm{R} \$ 650$ milhões de reais, apenas com a venda de $15 \%$ das projeções (no Plano Piloto de Brasília não se vendem lotes, mas projeções, segundo seu plano urbanístico tombado). Este bairro, que ainda se encontra como gleba e já licenciado junto ao Ibama, deverá, segundo informações obtidas junto à Terracap, cerca de 300 lotes, sendo que em cada lote será possível a construção de prédios de seis andares, com um total de 400 apartamentos, a um custo estimado (segundo o depoimento de alguns corretores imobiliários) de $\mathrm{R} \$ 1.200 .000,00$ por apartamento de três quartos com terreno situado na faixa de R\$7000,00 o metro quadrado!!! Isto equivale à utilização ideológica da "preservação do meio ambiente" na construção dos valores que os imóveis já agregam.

15. O Projeto de lei complementar do Plano Diretor de Ordenamento Territorial do Distrito Federal (PDOT), capítulo V - Do desenvolvimento econômico --, artigo 35, item I, que trata sobre "urbanizar e qualificar os espaços públicos por meio da reestruturação, complementação ou implantação da infraestrutura urbana, dos equipamentos públicos e do sistema de transportes" (p.13), atesta nossa afirmativa das infraestruturas para atender a gestão urbana.

16. Refere-se às vias L4 Norte e L3 Norte, que foram inauguradas em 28/8/2005, pela então governadora Maria de Lourdes Abadia, sob a justificativa de melhorar o trânsito nessas vias do Plano Piloto, uma vez que elas facilitaram o acesso entre setores estratégicos e possibilitaram uma fluidez mais rápida para os futuros moradores do Setor de Habitações Noroeste, para os futuros usuários da Cidade Digital à Universidade de Brasília, à orla do Lago Paranoá (o atual governo já tem "novos" projetos de revitalização da área e vem promovendo o turismo), à Esplanada dos Ministérios e ao aeroporto. Na reforma do sistema de transporte coletivo, o Plano Piloto terá veículo leve sobre trilhos (VLT). O anúncio feito, na época, pelo governador Arruda, antes de uma viagem à Europa, onde conheceria os sistemas de transporte público adotados por diversos países, em decisão tomada depois de um estudo elaborado por representantes do decanato de extensão da UnB, do Instituto Geográfico e Histórico do DF, dos conselhos comunitários e outras instituições (a reportagem do Jornal de Brasília de 31/5/2007, Informe DF, p. D4, não especifica quem seriam essas instituições, nem quais conselhos comunitários participaram desse estudo). 
17. Segundo o depoimento do atual governador do Estado de Goiás, Alcides Rodrigues, a vinda da TAP Portugal, abre um novo corredor para Goiás, pois possibilitará um intercâmbio maior de turistas vindos da Europa para o Centro-Oeste. Portugal, como porta de entrada para a Europa, dinamizará o comércio do Centro-Oeste para este continente (Jornal da Comunidade, Caderno Especial. Brasília, 14 a 20/7/2007, p.2).

\section{RESUMOS}

Esse artigo tenta compreender a organização do território urbano à luz das relações capitalistas contemporâneas, em que a forma fictícia do capital ganha relevância. A urbanização tanto produz uma expectativa de valorização para diversas frações do capital como sofre influência dele, especialmente em sua forma fictícia. Do ponto de vista metodológico, a teoria marxiana do valor, o capital fictício e o uso do território urbano constróem nossa argumentação. Em termos empíricos, cabe destacar como as políticas urbanas são influenciadas pelo capital fictício na organização do espaço das cidades. Cumpre aos gestores urbanos tornar as cidades atrativas aos fluxos de capital, o que implica em uma infraestrutura específica para os grandes negócios financeiros.

Cet article vise à comprendre l'organisation du territoire urbain à la lumière des relations capitalistes contemporaines, où la forme fictive du capital acquiert une importance grandissante. D'un côté, l'urbanisation produit une expectative de valorisation pour différentes fractions du capital, de l'autre côté elle souffre son influence, surtout dans sa forme fictive. Du point de vue méthodologique, la théorie marxiste de la valeur, le capital fictif et l'utilisation du territoire urbain fondent notre argumentation. En termes empiriques, il faut remarquer que les politiques urbaines sont influencées par le capital fictif dans l'organisation de l'espace des villes. C'est aux décideurs urbains de rendre les villes attractives pour les fluxes de capital, ce qui implique une infrastructure spécifique pour les grades affaires financières.

This paper aims to understand the organization of urban territory dealing with present capitalist relations, where the fictive form of capital assumes relevance. Urbanization produces an expectative of valorization for different capital's segments, as well as it suffer its influence, namely in its fictive form. On a methodological standpoint, the Marxist theory of value, fictive capital and utilization of urban territory structure our arguments. In empirical terms, we stress that the urban politics are influenced by fictive capital in the organization of the cities' spaces. Urban deciders have to render cities attractive for the capital fluxes, what implies specific infrastructure for the great financial business.

Este artículo intenta comprender la organización del territorio urbano a la luz de las relaciones capitalistas contemporáneas en que la forma ficticia del capital gana relevancia. La urbanización tanto produce una expectativa de valorización para diversas fracciones del capital como recibe influencia de él, especialmente en su forma ficticia. Desde el punto de vista metodológico la teoría marxista del valor, el capital ficticio y el uso del territorio urbano construyen nuestra argumentación. En términos empíricos, cabe destacar como las políticas urbanas son influenciadas por el capital ficticio en la organización del espacio de las ciudades. Es tarea de los gestores urbanos convertir a las ciudades en atractivas para los flujos de capital, lo que implica una infraestructura específica para los grandes negocios financieros. 
ÍNDICE

Mots-clés: territoire, urbanisation, capital fictif, politiques urbaines, capitalisme

Keywords: territory, urbanization, fictitious capital, urban politics, capitalism

Palavras-chave: território, urbanização, capital fictício, políticas urbanas, capitalismo

Palabras claves: territorio, urbanización, capital ficticio, políticas urbanas, capitalismo

\section{AUTORES}

ROSÂNGELA VIANA VIEIRA NERI

Doutoranda em Geografia pelo IESA/UFG, rvianavieira@gmail.com

\section{FÁBIO MARVULLE BUENO}

Doutorando em Sociologia pela UnB, fmbuenobr@yahoo.com.br 